\title{
AS CRISES DAS DEMOCRACIAS E AS REVOLUÇÕES DAS CORES
}

\author{
LAS CRISIS DE LAS DEMOCRACIAS Y LAS REVOLUCIONES DE LOS \\ COLORES
}

THE CRISES OF DEMOCRACIES AND THE COLOR REVOLUTIONS

\author{
Jaime TAMAYO ${ }^{1}$ \\ Daniela IÑIGUEZ ${ }^{2}$
}

RESUMO: No presente artigo pretende-se fazer um estudo comparativo entre as mobilizações ocorridas no espaço pós-soviético conhecido como as "Revoluções das Cores" em contraste com o movimento mexicano de Andrés Manuel López Obrador. Analisamos movimentos que podem parecer semelhantes, porque eles lutam contra o autoritarismo ou versões alternativas da democracia depois de dias eleitorais acusados de resultados fraudulentos, mas vistos do aspecto geopolítico afetam os interesses do Ocidente - e particularmente dos Estados Unidos - de uma maneira diferente: triunfam ou são desacreditados, afetando o projeto neoliberal.

PALAVRAS-ChAVE: Democracia. Fraude eleitoral. Movimentos sociais. Espaço póssoviético. México.

RESUMEN: En el presente artículo se pretende hacer un estudio comparativo entre las movilizaciones que se dieron en el espacio post-soviético conocidas como las "Revoluciones de los Colores" contrastadas con el movimiento mexicano de Andrés Manuel López Obrador. Se analizan movimientos que pueden parecer similares porque luchan contra el autoritarismo o versiones alternas de la democracia tras jornadas electorales acusadas por resultados fraudulentos, pero vistos desde el aspecto geopolítico afectan los intereses de occidente - y particularmente de Estados Unidos - de forma diferente: ellos triunfan o son desacreditados, afectando el proyecto neoliberal.

PALABRAS CLAVE: Democracia. Fraude electoral. Movimientos sociales. Espacio postsoviético. México.

ABSTRACT: In the present article we intend to make a comparative study between the mobilizations that took place in the post-Soviet space known as the "Color Revolutions" in contrast to the Mexican movement of Andrés Manuel López Obrador. We analyze movements that might seem similar because they fight against authoritarianism or alternate versions of democracy after electoral days accused of fraudulent results but viewed from the geopolitical

${ }^{1}$ Universidad de Guadalajara (UDG), Centro Universitario de Ciencias Sociales y Humanidades, Guadalajara Jalisco - México. Profesor investigador del Departamento de Estudios sobre Movimientos Sociales. E-mail: tamayo_jaime@hotmail.com.

${ }^{2}$ Universidad de Guadalajara (UDG), Centro Universitario de Ciencias Sociales y Humanidades, Guadalajara Jalisco - México. Estudiante de la maestría en Ciencia Política. E-mail: daniela_decalleruda@ hotmail.com. 
aspect they affect the interests of the West -and particularly of the United States- in a different way, so they may triumph or are discredited, affecting the neoliberal project.

KEYWORDS: Democracy. Electoral fraud. Social movements. Post-Soviet space. Mexico.

\section{Introducción}

El fin del siglo XX pareció cerrar con la consolidación de la democracia en el mundo, la llamada Tercera Ola de la Democracia (HUNTINGTON, 1994) parecía que afianzaba a esta tanto en la zona de los golpes de Estado militares, en América Latina, como en el espacio de las cuestionadas "democracias populares" del socialismo realmente existente en el este de Europa, e incluso en el entorno de la ex-Unión Soviética.

Sin embargo, ni la democracia liberal constituía la panacea que auguraban los profetas del "Fin de la Historia" (FUKUYAMA, 1994) ni los movimientos por la democratización estaban exentos de interesesexternos. De hecho el siglo XXI ha estado marcado por una fuerte intervención, ya sea para impulsar dichos movimientos, ya sea para frenarlos. Se puede decir que:

La mundialización ha tenido también importantes impactos en la generación de movimientos sociales de corte político de nuevo tipo. Por una parte podemos decir que la democracia es hoy por hoy una de las banderas más importantes de los nuevos movimientos sociales. Pareciera que el siglo de las revoluciones violentas le ha abierto paso al nuevo siglo de las luchas pacíficas y los cambios democrático-electorales. Sin embargo, las luchas que se dan en su nombre no siempre desembocan en democracia, sino que por el contrario, en algunas ocasiones son canalizadas y reencauzadas por fuerzas regresivas o francamente sometidas a los intereses del neoimperialismo. (TAMAYO, 2013, p. 28-29).

En este sentido han surgido las llamadas "Revoluciones de las Flores" o "de Colores" que cada vez parecen estar más vinculadas a factores externos, si bien tienen como base movimientos legítimos de reclamos democráticos, al respecto Bautista (2018, s/p) las define como "un componente estratégico de las guerras de cuarta generación" y está diseñado para implosionar procesos democráticos inconvenientes para la hegemonía gringa. A diferencia del "golpe suave", no depende de la injerencia directa o de una orquestada propaganda mediática -exterior e interior- que interpele a las propias instituciones, para hacerlas patrocinadoras y ejecutoras de una destitución gubernamental... sino de la posibilidad de interferir en la propia gestión gubernamental para minar, desde adentro, la legitimidad que le sostiene. Por eso, 
según el propio Bautista "es conceptuada como una 'revolución,' porque aparece y se desarrolla mediante una 'transferencia de legitimidad', que crece inversamente proporcional a la pérdida de legitimidad del gobierno y que es, en última instancia, lo que acaba ungiendo a la oposición con un aura democrático y revolucionario".

Pero, ¿cuál es el contexto en el que surgen tales revoluciones? A finales de los ochentas la Unión Soviética experimentó un dilema, mientras que en algunas repúblicasse desataban grandes movilizaciones socialespara independizarse de Moscú sus economías se encontraban tan especializadas que dependían unas de las otras; la ruptura provocaría consecuencias adversas puesto que cada una fungía como un engranaje de la gran maquinaria que había cimentado el Partido Comunista.

Al frente de las nuevas repúblicas, producto de la desintegración, se posicionaron líderes que respondían al antiguo poder central, pero que a su vez procuraron una transición suavehacia la economía de mercado mediante acuerdos de cooperación y comercio con organizaciones y potenciasoccidentales como Estados Unidos y la Unión Europea, las cuales manifestaron la importancia de adoptar los valores liberales para el fortalecimiento de sus relaciones con la promesa de retribuciones. Un ejemplo de ello fueron los créditos del Fondo Monetario Internacional-FMI-, que golpearon a las economías a través de privatizaciones.

Por ejemplo, para 1999 la multinacional estadounidense AES Corporation compró Telasi - la compañía de distribución de electricidad georgiana-. AES-Telasi experimentó muchos conflictos con el pueblo ya que los precios no únicamente incrementaron estratosféricamente, sino que el reducido porcentaje de la ciudadanía que podía pagar padecía de constantes e indefinidos apagones, esto como resultado de un círculo vicioso en el que convergían tres cuestiones: al haber pocos clientes que remuneraban al servicio eléctrico, el capital producido no era suficiente para retribuir a los abastecedores de gas, sin el cual no podía generarse electricidad; sin mencionar las dificultades técnicas para abastecer a los consumidores. Finalmente en agosto de 2003 AES-Telasi fue vendida a la empresa rusa United Energy Systems, esto por el escándalo Enron, revelado en octubre de 2001.

No obstante, los tecnócratas respondieron a las medidas con habilidad. En Ucrania, después de la desintegración del banco soviético Gosbank, donde Víktor Yúshchenko inició su carrera, aquel ocupó el puesto de vicepresidente del JSC Agroindustrial Bank Ukraina y después pasó a ser el supervisor del Banco Nacional de Ucrania. A finales de los noventa, el Parlamento Ucraniano - la Rada Suprema - designó a Yúshchenko como dirigente de la bolsa. En dicho puesto logró aplazar la completa introducción de la grivna -moneda nacional-, donde ésta y el karbóvanets - el rublo ucraniano -, en un periodo de transición, circularon 
juntos para evitar la hiperinflación y progresivamente hacer uso exclusivo de la grivna para fortalecer las finanzas durante la crisis financiera de Rusia en 1998.

A nivel internacional, Yúshchenko arregló un eficiente sistema de pagos de la deuda, el desbloqueo del diálogo crediticio con el FMI, la disminución de la circulación del dólar respecto a la grivna y restricciones para el cambio de divisas y la privatización del patrimonio industrial y de la tierra.Ante sus acertadas políticas económico-financieras, para 1999, Yúshchenko fue nombrado primer ministro.

Como primer ministro Yúshchenko promovió la privatización, la reducción de la inflación, equilibrar el presupuesto nacional, recortó la nómina de la burocracia gubernamental y creó medidas anticorrupción -particularmente en el sector energético-, y con ello pudo pagar las pensiones a retirados y salarios atrasados de profesores, trabajadores para la salud, entre otros (KARATNYCKY, 2005).

El modelo económico que siguió tanto Georgia como Ucrania es un ejemplo de los reajustes financieros que acercaron a Europa del este a occidente, pero no era suficiente.Occidente procuró su seguridad con la continuidad de la Organización del Tratado del Atlántico Norte (OTAN), a pesar de que su función era ser la contraparte del extinto Pacto de Varsovia, pero los vestigios del pasado han prevalecido. En 2004 se llevó a cabo la gran quinta ampliación que comprendió a Bulgaria, Eslovaquia, Eslovenia, Rumania y a las repúblicas ex soviéticas de Estonia, Letonia y Lituania.Para entonces Moscú no había alcanzado el poder político necesario para hacer réplica, por lo que, a través de la carta democrática, dio inicio la conquista del este por Estados Unidos.

\section{Las Revoluciones de Colores}

Schumpeter (1963) determina que, de acuerdo con la filosofía de la democracia del siglo XVIII, el método democrático consiste en delegar poder a ciertos individuos para que estos, como los representantes de la mayoría, busquen a través de políticas el bien común, pero tal postura ha quedado relegada por muchos factores; uno son los movimientos sociales, en este caso las Revoluciones de Colores, ya que incidieron directa y activamente en las decisiones políticas sobre el bien común; pero "el bien común ha de significar necesariamente cosas diferentes" (SCHUMPETER, 1963, p. 322-323). Donde esto se tornó más evidente fue en Ucrania, donde no puede existir aquello denominado como "voluntad general" debido a la 
división del país entre nacionalistas y pro-rusos, por lo tanto, tampoco puede existir la idea del bien común.

Pero, ¿qué representaba el bien común para los manifestantes? Las protestas demandaron elecciones democráticas, libertad política, la renuncia de los líderes autoritarios, la adhesión de su país a la Unión Europea y relaciones estrechas con Estados Unidos. Pero la idea de la occidentalización de los países post-soviéticos partía de grupos y líderes políticos y sociales apoyados, influenciados y financiados por Estados Unidos.

De acuerdo con Moscovici (1985), los líderes son los que dan razón y cohesión al movimiento, y plantea que "en nuestras sociedades de masa, el arte de agitar a las multitudes, la política, es una religión” (p. 15). Aquí "los individuos tienen la ilusión de decidir por sí mismos, sin darse cuenta de que han sido influidos o sugestionados" (MOSCOVICI, 1985, p. $30)$.

Tras hacer una evaluación del costo/beneficio respecto a las relaciones con la Federación Rusa, parece incoherente decantar por una dirección política occidental, pero "en la lucha de la razón contra la pasión, la pasión gana siempre” (MOSCOVICI, 1985, p. 32).

Cuanto más débil sea el elemento lógico en la formación de la opinión pública, y más completa la falta de crítica racional de la influencia racionalizadora de la experiencia y la responsabilidad personales, mayores son las oportunidades para los grupos que persigan fines interesados. (SCHUMPETER, 1963, p. 336).

De hecho, "la voluntad que observamos al analizar los procesos políticos no es ni con mucho una voluntad auténtica, sino una voluntad fabricada (...), la voluntad del pueblo es el producto y no la fuerza propulsora del proceso político" (SCHUMPETER, 1963, p. 336).

Sin embargo, independientemente de que si las Revoluciones de Colores responden a intereses externos, las tácticas de algunos de los regímenes post-soviéticos para perpetuarse en el poder distan de responder a la voluntad del pueblo. Aquí "tenemos que juzgar la plausibilidad de los derechos humanos como un sistema de razonamiento ético y como la base de las demandas políticas (SEN, 2000, p. 229-230).

Sen (2000) se refiere a los valores asiáticos como instrumentos políticos para justificar prácticas gubernamentales autoritarias y para sostener relaciones diplomáticas llevaderas, y se plantea: “ilos valores asiáticos se oponen - o son indiferentes - a los derechos políticos básicos?” (p. 231). Aunque Sen (2000, p. 247) resalta que Estados Unidos y Europa enaltecen la importancia de la libertad política y la democracia, así como que "el reconocimiento de la diversidad dentro de las diferentes culturas es extremadamente importante en el mundo 
contemporáneo", Estados Unidos podía - y ha podido - extender su influencia bajo pretensiones aparentemente "desinteresadas" como en actividades de asistencia democrática, promoción de la democracia y/o apoyo a la sociedad civil que fueron herramientas sumamente utilizadas bajo los gobiernos de Bill Clinton y George W. Bush en beneficio de los intereses estadounidenses, de hecho, éstos presidentes impulsaron las denominadas Revoluciones de Colores.

La seguridad y los intereses de Estados Unidos son de importancia internacional, "aunque la hipótesis de trabajo de la política exterior norteamericana consistía en favorecer la diversidad en el mundo, el resultado habitual era presionar para que hubiera uniformidad" (TAYLOR; FLINT, 2002, p. 104). Como el tipo de democracia que deben tener los Estados.

¡Para salvar la democracia hay que destruirla! (...) Como en todas las estrategias de política de poder, los débiles sufren a manos de los fuertes, el equilibrio de poder es lo más importante y no se puede consentir que los países pequeños lo estropeen. (TAYLOR; FLINT, 2002, p. 105).

La globalización entra aquí como un arma de doble filo, si bien "coloca a los gobiernos bajo creciente escrutinio" para juzgar su conducta respecto al bien común, como el desempeño de las políticas económicas (CHEEMA, 2005). Esto trabaja en beneficio del sistema capitalista.Con ayuda de occidente, la transición de los países post-soviéticos implicó la introducción de nuevas economías al sistema capitalista, pero para las nuevas repúblicas se trató de una trampa para osos. A estas alturas Estados Unidos y demás aliados tomaban ventaja de las debilitadas repúblicas entonces recién independizadas y se mostraron beneplácitos ante la entrada del este europeo al "mundo civilizado".

Occidente intenta -y seguirá intentando- mantener su posición preeminente y defender sus intereses definiéndolos como los intereses de la $<<$ comunidad mundial > . Esta expresión se ha convertido en el eufemismo colectivo sustituto de <<el mundo libre>>- que se utiliza para dar legitimidad universal a medidas que responden a los intereses de los Estados Unidos y otras potencias occidentales. (HUNTINGTON, 2001, p. 218).

\section{La Revolución Buldócer}

Las Revoluciones de Colores, como herramienta de Washington para aumentar su espacio de influencia, partieron con la Revolución Buldócer, que derribó al gobierno nacionalista serbio de Slobodan Milosevic y contó con el apoyo velado tanto de Estados Unidos como del empresario húngaro-estadunidense George Soros, quien detrás de la Open 
Society Institute -ahora Open Society Foundations- se encargó de hacer enormes concesiones financieras a ciertas Organizaciones No Gubernamentales (ONG).

Asimismo, el Instituto Nacional Demócrata para los Asuntos Internacionales, que fundó la política estadounidense Madeleine Albright, fomentó y subvencionó los principios de la Open Society en Serbia, Georgia, Ucrania, Kirguistán, Bielorrusia, Moldavia e incluso en Rusia, así como el Instituto Internacional Republicano (IIR). Del IIR depende la Freedom House, organización que se encargó, entre otras cosas, de defender la libertad de prensa y financiar diarios independientes de oposición en las repúblicas ex soviéticas. Tales institutos se desprenden de la U.S. Agency for International Development (USAID), cuya misión es exportar la democracia y formar economías de mercado. Con anterioridad, las tareas para derrocar gobiernos comunistas o dictatoriales estaban a cargo de la Agencia Central de Inteligencia (CIA), por sus siglas en inglés-, pero actualmente se manejan de una manera más transparente y pública. Este fue el legado de Clinton.

La política de intervención abierta de Clinton experimentó un gran éxito al interior del Estado yugoslavo, donde se encontraba un fragmento de la población hastiada del régimen de Slobodan Milosevic.Este grupo estaba conformado por jóvenes activistas serbios que se identificaban bajo el nombre de OTPOR (Resistencia), un movimiento en favor de la democracia. OTPOR emprendió una intensiva campaña contra Milosevic a partir de los ataques aéreos de la OTAN del 24 de marzo de 1999 -prolongándose durante 78 días mássobre Yugoslavia. El cometido de OTPOR era romper con la apatía política de los ciudadanos, donde no se trataba de favorecer a ningún partido o individuo sino, esencialmente, derribar a Milosevic a través de elecciones justas.

OTPOR actuó a partir del financiamiento de Estados Unidos y algunos países europeos que a su vez proporcionaron personal y material didáctico para planificar y efectuar una revolución pacífica, aquí se tomó como base teórica la obra: De la dictadura a la democracia. Un sistema conceptual para la liberación de Gene Sharp, fundador del Instituto Albert Einstein, organización que promueve rebeliones no violentas en el mundo.

El ensayo de Sharp fue publicado por primera vez en 1993 y a partir de entonces se ha traducido a muchos idiomas y activistas democráticos lo han difundido de forma gratuita en sus respectivos países dictatoriales. El libro advierte sobre el papel de las fuerzas externas porque "si interviene otro Estado, probablemente no deba confiarse en él" (SHARP, 2011, p. 7). Los Estados siempre actuarán en beneficio de sus intereses económicos y/o políticos; incluso occidente, como representante de la democracia, beneficia dictaduras. Lo que Sharp (2011) establece como el mejor tipo de asistencia del extranjero son las presiones 
internacionales como las sanciones económicas, la expulsión de organizaciones internacionales y ruptura de relaciones diplomáticas en favor del movimiento.

Asimismo, Sharp (2011) enfatiza en el valor de la resistencia y la inutilidad de las negociaciones, ya que finalmente no llevan a ningún lado y ninguna dictadura es invulnerable, atacar su poder político, compuesto por autoridad, recursos humanos, conocimiento y destrezas, factores intangibles, recursos materiales y maquinaria de seguridad,debilitaría y terminaría por paralizar al gobierno; otro factor pro-democrático son las instituciones no gubernamentales, porque la formación de grupos independientes implica la creación de grupos de presión; y que la vía no violenta será siempre la respuesta a través de sus tres categorías: protesta ypersuasión, no cooperación e intervención.

De acuerdo con Sharp (2011), la no violenciaproduce los cambios más significativos, de lo contrario la resistencia perderá ante el Estado; para esto desarrolla la idea del desafío político, el cual ataca a las dictaduras mediante estrategias, tácticas y métodos; ante todo esto la finalidad es establecer un sistema democrático e impedir el surgimiento de una nueva dictadura. El trabajo de Sharp es mucho más detallado, incluso hay un apéndice sobre la acción no violenta, que es un desplegado de 198 métodos de protesta y persuasión que puede adecuarse y acomodarse a las necesidades y posibilidades de cada sociedad civil ante una dictadura, ninguna es igual pero el ensayo de Sharp puede adecuarse por su cualidad genérica.

Después de actividades y eventos apegados al manual, los jóvenes de OTPOR y observadores electorales aguardaron por el sufragio. Para el 25 de septiembre del 2000 se anunció el triunfo de Vojislav Kostunica, líder de la oposición, pero Milosevic rechazó y anuló los resultados. El mismo día se llevó a cabo una concentración masiva de manifestantes que ocuparon el parlamento de Belgrado, declarándose una guerra no violenta en Yugoslavia, entonces dio inicio la Revolución Buldócer -llamada así por el empleo de maquinaria pesada para replegar a los policías-, la movilización que marcaría la pauta para las Revoluciones de Colores. Finalmente Milosevic fue derrocado y para 2001 fue "detenido, acusado de corrupción y abuso de poder [...] entregado al TPIY, en La Haya, acusado de crímenes de guerra. En el posterior juicio, se amplió la acusación y fue inculpado también por crímenes en Bosnia y Croacia" (EL PAÍS, 2011).

Pero el movimiento serbio no terminó ahí, fue a través de la proporción de becas para estudiar en Estados Unidos, así como viajes para asistir a cursos con los líderes estudiantiles que encabezaron los movimientos para instruir a jóvenes y futuros dirigentes para la creación de más organizaciones golpistas, pero ahora en el espacio post-soviético. Tal es el caso de KMARA (¡Suficiente!), movimiento estudiantil de desobediencia civilde la República de 
Georgia, que recibió entrenamiento de OTPOR, entonces rebelión juvenil pro democrática y ahoraconocida como CANVAS Belgrado, grupo de entrenamiento financiado por Estados Unidos.

\section{La Revolución de las Rosas}

Kandelaki (2006), como cofundador de KMARA, afirma quesi bien el movimiento "fue vital durante la Revolución de las Rosas combatiendo la apatía política y alentando el activismo político y la participación" (p. 8), también menciona que otros factores incidieron en la sublevación georgiana, y hace referencia a la estación de radiofusión televisiva Rustavi2, al Movimiento Nacional de Mijaíl Saakashvili, a la sociedad civil y a actores internacionales.

Rustavi-2 es una empresa independiente en Georgia que transmitió semanalmente los resultados de las encuestas de opinión patrocinadas por la Open Society Georgia Foundation, USAID y el Consejo Británico (WELT, 2005). Asimismo, Rustavi-2 emitía las actividades y declaraciones de la oposición, con lo que alentó a la gente a sumarse al movimiento liderado por Saakashvili.

Las masas, consideradas como meros significantes materiales, pueden ser manipuladas. Prácticamente cada reporte en la prensa georgiana y rumorología incluyó alguna observación, con diversos grados de aceptación editorial, que detrás de las reuniones destacaron "fuerzas políticas específicas", quienes organizaron, controlaron, y fueron financiadas, en la búsqueda de sus propios intereses privados. (MANNING, 2007, p. 194).

Para el 2 de noviembre de 2003 se celebraron elecciones parlamentarias, donde también se encontraba presente la Office for Democratic Institutions and Human Rights ODIHR- de la Organización para la Seguridad y la Cooperación en Europa -OSCE-. La ODIHR envió un total de 34 expertos electorales y 389 observadores provenientes de 43 Estados (OSCE, 2003). De igual forma hizo seguimiento la Asociación Georgiana de Jóvenes Abogados, el Liberty Institute, la Sociedad Internacional para Elecciones Justas y Democracia, y la Plataforma Europea para Elecciones Democráticas. De ante mano organizaciones e instituciones pronosticaron un ambiente adverso en el proceso electoral.

Georgia había sido gobernada por Eduard Shevardnadze desde 1992 -como presidente desde 1995-. Su gobierno - y su propia família - se veían cada vez más asociados con la rampante corrupción que limitaba el crecimiento económico de Georgia, por lo que el país 
seguía siendo muy pobre para los estándares europeos. Además, dos regiones separatistas apoyadas por los rusos - Abjasia y la también llamada Osetia del Sur- se mantenían fuera del control central de Tbilisi - la capital-, y la república autónoma de Adjaria estaba gobernada por el líder semi-separatista Aslan Abashidze. La crisis política y económica estaba cerca de alcanzar su cúspide momentos antes de las elecciones parlamentarias. De hecho, la alianza política de Shevardnadze, Por una Nueva Georgia (PNG), y de Abashidze, Unión por el Renacimiento Democrático, se vieron desplazadas por los populares partidos de la oposición: el Movimiento Unidad Nacional de Saakashvili y Demócratas-Burdzhanadze, liderados por la portavoz del parlamento, NinoBurdzhanadze,y por el - ahora fallecido - ex-portavoz Zurab Zhvania.

Pero los resultados oficiales establecieron el triunfo del PNG, seguido por Movimiento Nacional y, en tercer lugar, se hallaba Renacimiento. No obstante, "en sólo dos días, el panorama cambió radicalmente cuando los resultados electorales de la región autónoma de Adjara propulsaron al partido regional Renacimiento al segundo lugar" (KANDELAKI, 2006, p. 4). Mientras tanto, las votaciones tabuladas por diferentes entidades expusieron que Movimiento Nacional se colocaba en primer lugar, a continuación el PNG seguido por el Partido Laborista (WELT, 2005).

A pesar de que en el conteo extraoficial Movimiento Nacional no había recibido una desorbitante cantidad de votos, la cantidad de papeletas en apoyo al partido de Abashidze, según la Comisión Electoral Central -CEC-, era improbable. De igual manera se registraron una serie de anomalías referentes a las listas del padrón, que incluían a ciudadanos fallecidos, impidió la participación de votantes activos y en demás casosse permitió ejercer múltiples votos, e igualmente alarmante fue la omisión de la entrega de boletas a los centros de votación (MITCHELL, 2004). A pesar de todo, el 20 de noviembre fueron anunciados los resultados oficiales y quedó establecido el cuerpo parlamentario favorable al régimen.

Y el 22 de noviembre, cuando se llevó a cabo la sesión de apertura del nuevo parlamento, la oposición y sus partidarios avanzaron sobre la avenida Rustaveli de la capital,empuñando rosas rojas, reclamándose nuevas elecciones y la dimisión de Shevardnadze. Encabezados por Saakashvili marcharon hasta el edificio del parlamento, finalmente irrumpieron en éste e interrumpieron el discurso inaugural de Shevardnadze, quien inmediatamente abandonó el inmueble protegido por su escolta. El mismo día, después de escapar de la aglomeración de personas que abarrotaban el parlamento y calles aledañas, el presidente Shevardnadze manifestó su disposición a negociar la fecha de las elecciones 
presidenciales y/o realizar otro referéndum parlamentario siempre y cuando cesasen los disturbios.

Posteriormente, Shevardnadze declaró el estado de emergencia, pero las fuerzas armadas se habían unido a la oposición. Para el 23 de noviembre Shevardnadze se reunió con los líderes de oposición: Saakashvili, Burdzhanadze yZhvania bajo la mediación del ministro de relaciones exteriores ruso Igor Ivanov. Después de que finalizó el encuentro, Shevardnadze renunció a su puesto como presidente de Georgia para evitar, en sus palabras, "un derramamiento de sangre".

Para entonces el poder ya se había depositado en manos de los ministerios de defensa e interior y Burdzhanadze pasó a ser presidenta interina, acreedora de todos los poderes del presidente, y con ello, suprimió el estado de emergencia y convocó a nuevas elecciones, tanto presidenciales como parlamentarias y las programó para principios de 2004

El 4 de enero de 2004, con una participación del 80 por ciento, Saakashvili fue elegido presidente de Georgia con el 96 por ciento de los votos; Burdzhanadze retomó su puesto como presidenta del parlamento y Zhvania se posicionó como primer ministro. El Movimiento Nacional - aliado con los Demócratas - obtuvo un 67 por ciento de los asientos en las elecciones parlamentarias del 28 de marzo; sin embargo, "el régimen político post revolucionario en Georgia fue desde el principio una especie de mezcla de elementos democráticos y autoritarios" (PAPAVA, 2009, p. 2). Y aunque la segunda Revolución de Color tomó lugar casi inmediatamente en Ucrania, las circunstancias eran muy distintas.

\section{La Revolución Naranja}

El 31 de octubre de 2004 se llevaron a cabo elecciones presidenciales en Ucrania. Entre veinticinco aspirantes, Víktor Yúshchenko y Víktor Yanukóvich obtuvieron un resultado casi parejo con un 39.9 y 39.3 por ciento de los votos respectivamente, y como ningún candidato llegó a la mayoría absoluta, para el 21 de noviembre se llevó a cabo la segunda vuelta.

Cabe destacar que con los primeros comicios se mostró la división de Ucrania entre el candidato ruso-parlante del Partido de las Regiones, Yanukóvich, ex primer ministro y ex gobernador de Donetsk, favorito del este y el sur, crítico activo de la política exterior estadounidense; enfrentado al pro-occidental del partido Nuestra Ucrania Yúshchenko, 
semblante de las protestas contra el antiguo régimen. Por lo tanto, los triunfos electorales suelen ser determinados por el centro de Ucrania.

En este caso Yúshchenko disfrutó del apoyo del Canal 5, la estación televisiva del empresario y actual presidente de Ucrania, Petró Poroshenko, que transmitió los resultados de encuestas electorales financiadas por Estados Unidos y demás países occidentales, así como las actividades de organizaciones juveniles como PORA (¡Es hora!). Tal grupo trabajó en el "desarrollo de una estructura organizacional, formación de una estrategia de campaña, entrenar activistas, una campaña de información, respuestas ante la represión, y movilización por elecciones libres y justas" (ÅSLUND \& MCFAUL, 2006, p. 6).

Pero, así como en Georgia, se advirtió el registro de individuos fallecidos, se negó la participación a algunas personas y se le permitió a otras ejercer múltiples votos - gracias a autobuses que facilitaron su traslado de un lugar a outro -, hubo presencia simultánea de familiares en las casillas, compra de votos, se anuló el derecho al voto a domicilio, boletas encontradas en la basura, entre otras cosas

De igual manera, la CEC dio la victoria a Yanukóvich con un 49.5 sobre el 46.6 por ciento de Yúshchenko, lo que desató un gran levantamiento en Kiev. Esa noche, Yúshchenko y Yulia Timoshenko hicieron un llamamiento a los ucranianos para tomar la Plaza de la Independencia o Maidán, "símbolo de revolución, resistencia, y oposición" (YORK; MERRIMAN; ZIMMERMAN; BOAZ, 2010, p. 4). Y les solicitaron marchar hacia la administración presidencial y montar tiendas de campaña alrededor, así como bloquear los principales edificios gubernamentales, carreteras, aeropuertos y oficinas postales.

Canal 5, ERA-TV y Ukrainska Pravda difundieron el día a día de los acontecimientos, a diferencia del UT1, 1+1, STB, ICTV y Novy Kanal controlados por el Estado. Se transmitió en vivo el traslado del contingente al parlamento, la toma de protesta simbólica de Yúshchenko como presidente de Ucrania y a los manifestantes de pie cubiertos con sus impermeables anaranjados a merced de las bajas temperaturas. Se mostró la manera en que fraternizaban con la policía, dormitando en las tiendas y albergues, recibiendo comida, medicamentos, mantas, calcetines y botas, en parte proporcionado por ONG occidentales y en parte por los propios ucranianos nacionalistas, movilizados por el sentimiento que emanaba de sus radios y monitores.

Por otro lado, simpatizantes de Yanukóvich asistieron a la tumultuosa Maidán para la defensa de los resultados electorales y aseveraron que su candidato incrementó las pensiones y salarios, impidió la clausura de industrias sentenciadas por las reformas de mercado y que con él el vínculo con Rusia será más fuerte y se reflejará en el desarrollo y la estabilidad de 
Ucrania (KOLODIY; ZIELYK, 2007). No se trataba de resultados injustificados o inventados como los que los medios occidentales trataban hacer creer.

La cuestión es que cada candidato contaba con propuestas que los convertían en los favoritos de sus respectivas regiones.En el caso de Yanukóvich, éste "prometió la doble ciudadanía -ucraniana y rusa- así como dar a la lengua rusa un estatus oficial y simplificar el cruce fronterizo para habitantes de las regiones divisorias" (ZHURZHENKO, 2005, p. 67). Y Yúshchenko presentó un programa enfocado en la democracia y la liberalización del mercado, así como procurar la integración de Ucrania a la Unión Europea y a la OTAN.

Ciertamente, occidente y oriente votaron diferente, y fue un asunto que ocasionó divisiones significativas. El problema más grave fue que varias regiones orientales plantearon llevar a cabo referendos para autoproclamarse como regiones autónomas al interior de Ucrania (GUTIÉRREZ DEL CID, 2007). La crisis política condujo a una reunión entre el presidente Leonid Kuchma, los candidatos Yúshchenko y Yanukóvich, el presidente polaco Alexander Kwasniewski, el presidente lituano Valdas Adamkus, el alto representante de la Unión Europea, Javier Solana, y el vocero de la Duma, Boris Gryzlov, para "ayudar en estructurar un diálogo entre las fuerzas de oposición y disuadir a ambos lados de tomar acciones radicales o violentas, pero no resolvieron el conflicto" (ÅSLUND; MCFAUL, 2006, p. 2). El 3 de diciembre la Suprema Corte anunció la invalidación de los resultados de la CEC y se fijaron elecciones para el 26.

A los nuevos comicios acudió gran cantidad de observadores internacionales movilizados por occidente, y para el 28 de diciembre el balance de poder cambió. Yúshchenko - quien denuncio que había sido envenenado durante la primera campaña - y la Revolución Naranja - por el color del partido Nuestra Ucrania- vencieron con el 52 por ciento y "un día después de su inauguración, Yúshchenko viajó a Moscú para su primera visita internacional oficial, de la que seguirían viajes a Varsovia, Bruselas, y Washington" (KARATNYCKY, 2005, p. 16).

En cierta medida, Yúshchenko buscó un equilibrio de poderes en Ucrania, pero una de las principales promesas fue la de iniciar el proceso de adhesión a la Unión Europea y ante todo figuraban los vínculos con Estados Unidos. Esto último también aplicó al caso de Kirguistán porque se trataba de un país sobre-endeudado dependiente económicamente de Estados Unidos, y este factor incidió para que se diera la Revolución de los Tulipanes. 


\section{La Revolución de los Tulipanes}

Iván Marcovic -líder de OTPOR-, Giga Bokeria - líder de KMARA - y Vladislav Kashiv - líder de PORA- tuvieron un gran peso en las Revoluciones de Colores que siguieron, principalmente en la de Kirguistán, país geoestratégicamente relevante por la frontera que comparte con China, la emergente superpotencia económica, y Afganistán.

Es importante detenerse un momento en el asunto de Afganistán puesto que, tras los eventos del 11 de septiembre, se instaló una base militar estadounidense - recientemente cerrada - en el territorio del aeropuerto internacional de Manas, cerca de la capital kirguiza: Biskek, en diciembre de 2001. El presidente ruso, Vladimir Putin, apoyó los esfuerzos de Estados Unidos contra el terrorismo islámico por el tema de Chechenia, la cuestión es que la Federación Rusa también mantiene una base militar pero como legado del periodo soviético y en la localidad de Kant, al norte de Kirguistán.

A pesar de que al presidente Askar Akáyev se le reconocen varias concesiones hacia occidente, la liberalización económica y estabilidad política, llegó a ser acusado por actos de corrupción, nepotismo y sospecha de fraude para las elecciones legislativas del 27 de febrero y 13 de marzo de 2005. Asimismo, en febrero de 2003 la Constitución fue reformada para que fuera casi imposible aplicar un proceso de destitución - impeachment- al presidente; el temor de la oposición era que el partido de Akáyev ganara y así poder reelegirse para las elecciones de octubre (BRILL, 2005).

Akáyev había reformado la Constitución en varias ocasiones y en cada una fortaleció ala figura del presidente sobre las demás fuerzas - el legislativo y el judicial -, se le conoció por la influencia que ejercía su esposa sobre él así como por colocar a sus familiares en puestos políticos e incluso por centralizarel poder - aún más - porque reemplazó a los servidores de los gobiernos locales por su gente; el asunto es que por tratarse de un país étnicamente fragmentado entre los kirguises, los rusos del norte y los uzbekos del sur, se había construido un sistema político de clanes que solían saber responder a sus respectivos poblados (ORUÉ, 2007).

La situación étnica es muy importante y delicada en Kirguistán por lo que, contra el pronóstico de Akáyev, quiénaseguró que ninguna Revolución de los Tulipanes - refiriéndose a las Revoluciones de Colores - se concretaría, bautizó al movimiento que lo derrocaría oficialmente el 4 de abril de 2005, cuando, tras huir del país, firmaría su declaración de renuncia en la embajada kirguiza en Moscú. 
Para el 4 de marzo estallaronmovilizaciones a nivel local, pero la resistencia iba adquiriendo más empuje; líderes de oposición se reunieron en el sur y llevaron a cabo una asamblea popular para el día 15, entre ellos estaba Kurmanbek Bakíev - líder del Movimiento Popular de Kirguistán- y Roza Otunbáyeva - co-fundadora del partido Ata-Jurt -, para exigir nuevas elecciones y la renuncia de Akáyev; entretanto, Félix Kulov, ex ministro de seguridad, pidió a las fuerzas de seguridad no atacar a los manifestantes que se concentraban en Biskek, que si bien realizaron saqueos e incendios, estos cesaron una vez que Kulov intervino (ORUÉ, 2007). La Revolución de los Tulipanes, sin embargo, tuvo algunos incidentes violentos, el más notable ocurrió en la ciudad del sur Jalal-Abad; además, al menos tres personas murieron durante el saqueo que se extendió por la capital nacional las veinticuatro primeras horas después de la caída del gobierno.

Posteriormente, Bakíev se convirtió en presidente con un aplastante 89 por ciento, pero su triunfo se atribuye a que el electorado confiaba en el trabajo conjunto con Kulov como primer ministro (ORUÉ, 2007). Bakíev se presentó con intenciones de reformar la política y la economía, pero muchos consideraron que había resultado deficiente porque empeoró drásticamente la situación económica y energética, incluso el gobierno de Dmitri Medvedev - entonces presidente de Rusia - le retiró su apoyo en marzo de 2010, y en abril, durante su segundo periodo, estalló una revuelta socialque lo depuso y reemplazó por Otunbáyeva como jefa de gobierno provisional.

Bakíev del sur y Kulov del norte habían reunido las diferencias culturales entre un sur tradicional y un norte rusificado en la esfera gubernamental; por esa razón decidieron no competir entre ellos, alcanzaron un pacto electoral en el que Kulov dio su apoyo a Bakíev; era el momento en que alguien del sur, una región sin muchas libertades políticas, dirigiera, por lo que tras la destitución de Bakíev la situación étnica se recrudeció (HUSKEY, 2006). Para entonces al sur del país se libraba un conflicto con un saldo de cientos de fallecidos y miles de refugiados (SPUTNIK, 2015). Ciertamente, el caso kirguiz mostró un lado más crudo de lo que puede provocar una Revolución de Color, y a estas alturas los líderes del espacio postsoviético estaban conscientes de la ola democrática que se avecinaba, tal es el caso de Bielorrusia.

\section{La Revolución de los Jeans}


Posteriormente a los eventos de la Revolución de los Tulipanes, el 16 de septiembre del mismo 2005, el Partido Democrático de Bielorrusia convocó a una manifestacióncontra el presidente Alexander Lukashenko por la desaparición de su líder, Dmitri Pavilchenko. A su vez, se conmemoraba la desaparición de dosoponentes del régimen: Viktar Hanchar vicepresidente del parlamento- y el hombre de negocios Anatoly Krasousky (SANNIKOV; KULEY, 2006). Durante la protesta la policía antidisturbios confiscó las banderas blancorojo-blanco de los asistentes, emblema del país en 1991 tras el colapso de la Unión Soviética, por lo que Mikita Sasim, del movimiento juvenil por una Bielorrusia democrática y europea: ZUBR, decidió sacarse su playera de mezclilla - jeans- y la ondeó, anunció que podría servir en lugar de sus banderas. El acto tuvo un impacto simbólico. A partir de entonces, miembros del Partido Democráticoy del movimiento juvenil usaron ropa de jeans y alzaron banderas color índigo los días 16 de cada mes como muestra de solidaridad. Todo apuntaba al advenimiento de una nueva Revolución de Color.

Sin embargo, bielorrusos que habían viajado a Ucrania para observar el proceso de la Revolución Naranja a su regreso fueron arrestados; se hizo todo lo posible para prevenir que la oposición se movilizase: organizar protestas, convertirse en miembro de ciertas organizaciones o hablar contra los intereses nacionales era penado; estaba prohibido entrenar gente para realizar protestas callejeras - esto desacreditaba la imagen internacional de Bielorrusia -, así como pedir ayuda a países y organizaciones internacionales (BURGER \& MINCHUK, 2006).

No podría hablarse de paranoia, puesto que en efecto había organizaciones con interés en derrocar al gobierno. "La televisión bielorrusa anunció que se había descubierto un suministro de artículos y tiendas militares fabricados en Estados Unidos en la frontera con Letonia, y la policía estableció un cuartel general de emergencia y comenzó a monitorear los centros de votación” (MARPLES, 2006, p. 97).

Los sujetos u objetivos por los que se crearon las políticas restrictivas fueron ZUBR, el Frente Malady - frente juvenil -, ONG u organizaciones civiles: Vyasna y Hrodna Ratusha - liderado durante un largo tiempo por el candidato de oposición Alexander Milinkevich-, iniciativas civiles de Gómel y Brest, la Asociación de Estudiantes Bielorrusos, la Preparatoria de Lenguas Bielorrusas, el Liceo Humanístico Bielorruso, campañas cívicas como Khopits! ¡Suficiente! - y Za Svabodu - Por la Libertad-, y activistas cívicos (SANNIKOV; KULEV, 2006).

Para el 19 de marzo de 2006 el movimiento llegó a agrupar entre 15 y 50 mil personas -las fuentes consultadas hicieron llegar a esa estimación-en Minsk, con la finalidad de 
oponerse a los resultados de las elecciones presidenciales que le dieron el triunfo a Lukashenko con el 82 por ciento de los votos. La OSCE criticó tanto el proceso como los resultados electorales, pero no cuestionaron el 97 por ciento de Saakashvili, o el 89 de Bakíev, el 92 de Shevardnadze en 1992 -cuando era un reformista- o el 93 de Heydar Aliev en Azerbaiyán en 1993 (BHHRG, 2006). Es un asunto de doble moral.

Las protestas empezaron en cuanto se cerraron las casillas, pero cada día había menos manifestantes, para el día 23 había unas 200 personas. En el caso de ZUBR, que aunque había recibido el apoyo de occidente como sus homólogos serbios, georgianos, ucranianos y kirguises, el gobierno bielorruso no iba a permitir una Revolución de Color. A diferencia de lo ocurrido en el Maidán, la Plaza de Octubre fue bloqueada, se cerraron las tiendas de comida y cafés, así como los baños públicos. En este caso no se les facilitó nada a los manifestantes.

El día 24 las autoridades enviaron a la policía antidisturbios para dispersar a aquellos que habían ocupado la Plaza de Octubre con casas de campaña. El 25se reagruparon unas 10,000 personas en la Avenida de la Independencia, se reunieron para atender declaraciones de los aspirantes a la presidencia Milinkevich y Alexander Kazulin en el Parque Yanka Kupala, de ahí marcharon hacia el boulevard Nyamiha y siguió un enfrentamiento brutal con la policía antidisturbios en la Avenida Dzerzhinsky (MARPLES, 2006). Muchos fueron encarcelados y reprimidos con dureza. Y así como a demás manifestantes, los candidatos Kazulin, Vladimir Neklyaev, Vital Rymasheuski, Andrei Sannikau y el favorito de occidente, Milinkevich, fueron arrestados.

Occidente, particularmente la Unión Europea, apoyó a Milinkevich -académico de ascendencia polaca- porque todo candidato con una plataforma reformista basada en privatizaciones de los servicios industriales y públicos servía a sus intereses (BHHRG, 2006). Yen cierta medida Milinkevich también era del gusto del pueblo porque ofrecía valores liberales mezclados con orgullo nacional (LETAIN, 2006). Pero el movimiento fracasó, asî como la movilización moldava: la Revolución del Twitter.

\section{La Revolución del Twitter}

En Moldavia, las elecciones parlamentarias del 5 de abril de 2009 declararon ganador al Partido Comunista y para el día siguiente se desataron una serie de manifestaciones en las calles de la capital, Chisinau, que denunciaron fraude electoral e insistieron en repetir los comicios a pesar de que la OSCE, con su desplegado de observadores, había dado su visto 
bueno.Entre la multitud había nacionalistas pro-rumanos o miembros de extrema derecha como Noua Dreapta; y para el 7 de abril se dieron actos violentos y la policía respondió con detenidos. Las ONG informaron que se habían llevado a cabo malos tratos y torturas.

El 7 de abril se adhirieron representantes de la oposición y a estas alturas el número de asistentes había ascendido a 10,000 personas. Se alzó la bandera de Rumania y de la Unión Europea sobre el edificio de la oficina presidencial y el parlamento, ambos fueron saqueados y prendidos fuego. La policía, después de múltiples arrestos, recupero el control hasta el día 8. Entre los manifestantes había serbios y un letón, Alex Grigorievs, de la National Democratic Institute, quienes fueron expulsados del país.

Los jóvenes movilizados mantuvieron contacto en Twitter con el distintivo \#pman, cuyas siglas refieren al nombre en rumano de la plaza más grande de Chisinau: Piata Marii Adunari Nationale, porque demás redes se encontraban bloqueadas. Twitter sirvió para difundir el asunto del recuento de votos, la desaparición o secuestro de compañeros, informar sobre los lugares de ocupación y desplazamiento, convocar a eventos y capturar noticias del exterior (JIMÉNEZ CANO, 2009).

Los manifestantes no eran solo anti-gubernamentales, sino que eran pro-occidentales, pro-Unión Europea y pro-unión con Rumania, de hecho, casi todos los tweets están escritos en rumano. A pesar de que Vladimir Voronin era pro-ruso cuando fue elegido presidente en 2001, para entonces se había inclinado hacia la Unión Europea, ya que la Federación Rusa le había dado su apoyo a los separatistas de Transnistria debido a que ahí hay tuberías de tránsito y plantas de energía rusas (MUNGIU-PIPPIDI; MUNTEANU, 2009). De hecho, la proximidad con occidente ayudó a que Voronin no respondiera de una manera tan dura hacia los manifestantes.

Una vez que se dieron a conocer resultados, las ONG señalaron o, mejor dicho, enaltecieron las denuncias electorales, como la votación múltiple, votación sin identificación, firmas falsas en las listas electorales, falta de transparencia en el conteo de los votos, entre otras actividades parecidas a las ocurridas en las elecciones georgianas, ucranianas, kirguises y bielorrusas.Finalmente se llevó a cabo el recuento de votos, pero no hubo cambios significativos.

Para formar gobierno, el Partido Comunista debió haber obtenido por lo menos 61 de los 101 asientos del legislativo, debido a que sólo contó con 50, no se pudo elegir presidente en dos sesiones continuas, por lo que se disolvió el parlamento y se convocó a elecciones anticipadas para el 29 de julio; entonces el Partido Comunista ganó 48, el mayor número, pero el Partido Liberal Demócrata consiguió 18, el Partido Liberal 15, el Partido Demócrata 13 y la 
Alianza Nuestra Moldavia 7; puesto que conjuntamente estosformaron la coalición Alianza para la Integración Europea, lograron la mayoría de escaños y pudieron nombrar al presidente del parlamento, más no al jefe de Estado (VENTILA, 2010).

Si bien las nuevas elecciones hicieron que se dificultara la mayoría a los comunistas, se considera una revolución fracasada porque esperaban que la Alianza para la Integración Europea lograra una aplastante victoria y la destitución de Voronin. Era ansiado un giro geopolítico con prospecciones al ingreso a la Unión Europea porque el primero de enero de 2007 Rumania se adhirió, por lo que se restringió la libre circulación de ciudadanos y mercancía moldavos (MUNGIU-PIPPIDI; MUNTEANU, 2009).

Otra de las cuestiones es que si el Partido Comunista poseía gran poder político implicaba seguir retrasándose el ingreso a la OTAN, además de los lazos que aún existían entre Voronin y Rusia. Por esto es que Estados Unidos decantó por la Alianza para la Integración Europea, la coalición de partidos de derecha; y para apoyarlos envió a miembros de la USAID, a dirigentes de la Fundación Eurasia del International Research and Exchanges Board, del Instituto Nacional Demócrata y del Instituto Internacional Republicano para direccionar el voto y canalizar a los indecisos; asimismo, envió observadores que conformaron la Coalición Cívica 2009 - amparada por la NED, USAID y Fundación Eurasia , que reunió a 70 ONG para informar sobre las irregularidades (HOTNEWS, 2013).

A pesar de que los supuestos fraudes electorales de Europa del este meritaron de la ardua vigilancia de occidente, concretamente de Estados Unidos, para asegurar el cumplimiento de la democracia; en México, respecto a las movilizaciones que se oponían a los resultados electorales de 2006 y 2012, prefirieron mirar hacia otro lado, ¿por qué? Es sencillo, movimientos que podrían parecer similares porque luchan contra un régimen autoritario - o versiones alternas de la democracia- responden a los intereses de occidente de manera diferente.

\section{México, ¿La Revolución Amarilla?}

El movimiento de Andrés Manuel López Obrador en Méxicodurante el proseso poselectoral de 2006, empezó como toda Revolución de Color: como una protesta no violenta ante elecciones fraudulentas, contó con el apoyo de coaliciones cívicas, con las nuevas tecnologías de la información y se planteó derrocar a la oligarquía. No obstante, los mexicanos no fueron respaldados ni contaron con herramientas o apoyo internacional que 
impulsara y maximizara los movimientos porque no respondían a los intereses geopolíticos de Estados Unidos. Un cambio de régimen no era idóneo.

Además, algunas Revoluciones de Colores de Europa del estetriunfaron porque "gobiernos autocráticos" que no son amigos de "gobiernos democráticos" pueden ser juzgados de acuerdo con los valores occidentales y los derechos humanos, por lo quepueden ejercer control sobre éstos. Por eso a países como Cuba o Venezuela se les imponen bloqueos, porque escapan del control de occidente.

La victoria de López Obrador se encontró frustrada durante 12 años porque no se adscribe al proyecto neoliberal, mismo que han suscrito plenamente los gobiernosdel Partido Revolucionario Institucional - PRI - y el Partido Acción Nacional (PAN) en los últimos 35 años. Por ello el gran capital se manifestó cotidianamente contrario a la llegada de López Obrador. De hecho, en 2006 los organismos de la cúpula empresarial y el propio presidente de la República, Vicente Fox, en una flagrante violación a la Constitución y a la ley en materia electoral, intervinieron abiertamente contra dicho candidato, lo que debió llevar a la anulación de las elecciones ese año, de hecho de nuevo en estas últimas elecciones, ahora con el amparo de un dócil Tribunal Electoral del Poder Judicial de la Federación, volvieron a la carga, por ejemplo, el Consejo Coordinador Empresarial en su desplegado: "Trabajamos por México" (2018), donde reivindicaban las ventajas que, a lo largo de los últimos sexenios, se vieron beneficiados pasando por encima a los derechos humanos, al medio ambiente y sembraron un camino lleno de corrupción que ahora temen pueda llegar a su fin, sin embargo en esta ocasión se vieron descalificados por una inmensa mayoría de pequeños y medianos empresarios que negaron sentirse representados por dicha élite.

En México, las movilizaciones por la democracia lleva más de un siglo (VIZCARRA, 2002), fue precisamente la exigencia del sufragio efectivo el factor desencadenante de la Revolución Mexicana en 1910, si bien puede decirse que las movilizaciones contras el fraude electoral de 1988 (LÓPEZ LEYVA, 2007) constituyen el antecedente más inmediato del movimiento de 2006.

En 2006, el abortado intento de desafuero fraguado desde el ejecutivo en colisión con la Suprema Corte no fue detenido por el poder legislativo, sino que este dio su aval con el juicio de procedencia que finalmente desaforó a López Obrador. La movilización de cientos de miles - se habló de 400,000 personas - y las críticas en la prensa internacional parecieron no detener la decisión de impedir que el candidato más viable de la oposición pudiera competir por la presidencia, sin embargo el aumento de las reacciones de movilización, junto con los señalamientos desde la misma Unión Europea, obligaron a tomar, ya no una medida 
jurídica, sino claramente política para desde el ejecutivo mismo dar marcha atrás a la decisión, acompañada de la renuncia del Procurador General de la República y de una iniciativa que no privara de derechos políticos a procesados, tal como se establece en acuerdos internacionales suscritos por México.

Ya el mismo día de la elección y sin conocerse los resultados comenzaron las denuncias de fraude y la movilización de los seguidores de López Obrador, en un movimiento que fue convocado con una propuesta sumamente mediática y movilizadora: "voto por voto, casilla por casilla”. La denuncia se centró en el fraude electoral que supuestamente se habría realizado durante la jornada, no en la inequidad por la intervención de la presidencia causal abstracta de nulidad. ¿Por qué? No es comprensible fácilmente ni deja ver con claridad el supuesto fraude, se trata de un argumento jurídico para las masas y perdió capacidad de movilización.

Se dio el desconocimiento de resolución aún antes de conocerse, la descalificación de los magistrados del tribunal por supuestas presiones y compra de voluntades. Las instituciones se fueron al diablo. Se llevaron a cabo movilizaciones de más de un millón y medio de personas - quizá de dos millones - y la toma de las principales plazas y calles de la capital. Las manifestaciones se desataron por todo el país.

Se formó la Convención Nacional Democrática como agrupación civil de resistencia, el Frente Amplio Patriótico como alianza de partidos previamente coaligados para la elección y el nombramiento del "presidente legítimo" y su gabinete - no de sombra. Sin embargo la Revolución Amarilla- el color se le atribuye al del Partido de la Revolución Democrática, por el que fue candidato López Obrador- no cuajaba, ¿por qué?

La transición democrática estuvo completada desde el 2000 debido a la reforma de 1996, la primera consensada por toda la oposición. Se estableció la autonomía plena de los órganos electorales -el fin del control por el ejecutivo y su partido-, la anulación del régimen legal de excepción de los asuntos electorales, se creó el Tribunal Electoral del Poder Judicial de la Federación, la judicialización y mayor autonomía de la Suprema Corte de Justicia con el Consejo de la Judicatura, la desaparición del Colegio y Tribunal Electoral como última instancia definitiva, la prohibición del corporativismo político -ciudadanización-, equidad en financiamiento y medios, ahora se pueden denunciar delitos electorales, se efectúa sanción a funcionarios públicos que desvían recursos y se crearon diversos mecanismos de controlpara garantizar la autenticidad del triunfo de los candidatos -mediante la ciudadanización de los funcionarios de casilla por sorteo, las boletas, el Programa de Resultados Electorales Preliminares, etc. (VIZCARRA, 2002, p.141-144). 
De hecho, los tres procesos previos - de 1997, 2000 y 2003 - con el dato duro de la alternancia confirmaron que se vivía en cierta normalidad democrática. Para entonces se había consolidado un sistema multipartidista fuerte y con partidos con arraigo, con elecciones competitivas en cuanto a una representación plural y se visibilizaba la división de poderes.

Para 2006, observadores internacionales habían considerado cubiertos los estándares democráticos, por lo que se ejerció presión a aceptar la resolución del tribunal y después condena internacional a la autoproclamación y a la intención de impedir toma de posesión, con ello hubo una pérdida de apoyo interno y credibilidad.Si no hubo fraude (PÉREZ FERNÁNDEZ DEL CASTILLO, 2008), ¿qué hubo?

Era evidente que hubo una intervención de la Presidencia de la República y los empresarios de manera ilegal y rompiendo la equidad electoral, que no fue frenada por el órgano electoral, que dicho sea de paso sus integrantes habían cambiado, y en la integración del Consejo General habían pactado los partidos antilopezobradorsistas, es decir el PRI y el PAN, por lo que violando el espíritu de las reformas realizadas durante el gobierno del presidente Ernesto Zedillo, que privilegiaban el consenso de las fuerzas políticas contendientes, se optó por el intercambio de posiciones de consejeros no sólo afines a los dos partidos, sino algunos de ellos militantes, como el propio presidente del Consejo, que había figurado recientemente como secretario técnico de la Comisión Nacional de Ideología del PRI (ZÁRATE, 2006). De esta manera aun cuando durante la jornada electoral difícilmente puede sostenerse que hubiera habido fraude, las acciones previas del Presidente Fox y de las cúpulas empresariales debieron llevar a la anulación del voto.

Sin embargo, López Obrador no optó por exigir dicha anulación sino por el recuento total de la votación, generando lo que ha constituido la mayor movilización de la que setenga registro en México, incluso el Financial Times (2006) llegó a hablar de que López Obrador se proponía realizar una nueva revolución en México a raíz de lo que consideraba el fraude electoral, no obstante, a diferencia de las Revoluciones de Colores en la ex Unión Soviética, las diversas fuerzas políticas y económicas del mundo cerraron filas junto a gobierno mexicano y el candidato oficialista cuestionado, de tal manera que las movilizaciones y la toma de los espacios públicos por cerca de dos millones de ciudadanos no bastó para revertir los resultados en los tribunales (LA JORNADA, 2006). Evidentemente un movimiento de lucha por la democracia que cuestiona al modelo neoliberal, no sólo no sería apoyado por el capital transnacional y los gobiernos imperiales, sino que sería descalificado con todo vigor.

Nuevamente López Obrador presentó su candidatura en 2012, ocasión en la que de nuevo perdió la elección en un cuestionado proceso (ACKERMAN, 2015, p. 179). Si bien en 
esta ocasión las irregularidades más relevantes tuvieron que ver con la compra masiva de votos a favor del candidato del PRI, y las movilizaciones no alcanzaron mayor fuerza. Sería hasta las elecciones de 2018 cuando finalmente, con una avalancha masiva de votos que hizo imposible cualquier manipulación o fraude electoral, que López Obrador alcanzó la presidencia de México.

\section{La transición democrática}

Posteriormente a su triunfo, las administraciones "de Colores" de Europa del este sucumbieron ante la corrupción, crisis económicas, políticas y sociales. Si bien tuvo que ver con la crisis del 2008 o el rol de Rusia como potencia regional, según los institucionalistas históricos "las instituciones contienen los significados residuales de la vida política que luego moldean las preferencias y el comportamiento de los actores" (BEVIR, 2010, p. 48).

Los tintes de un régimen no democrático hacen oscilar entre sus respectivas bifurcaciones de acuerdo con dimensiones como la participación, la justificación ideológica, la estructura institucional y el pluralismo (MORLINO, 2005). Que aquí refiere estrictamente a lo que Linz (1978) llama "pluralismo limitado" o, como lo denomina Morlino (2005), "coalición dominante".

Uno de los rasgos más distintivos del pluralismo limitado sugiere el establecimiento de un partido oficial o único que se encuentra nutrido por una mentalidad y una ideología que le da sentido al régimen; la cuestión es que mientras haya quienes no se sientan representados por el régimen, habrá oposición, como la que se organizó en Serbia, Georgia, Ucrania, Kirguistán, Bielorrusia, Moldavia o México. En este contexto debe señalarse que "la liberalización de los regímenes autoritarios puede llegar lejos, pero [...] sin la institucionalización [...] corre el riesgo de quedar en nada" (LINZ, 1978, p. 25).

El movimiento y la institución se contraponen dialécticamente, pero tienen en común una sustancia profunda. La institución, en efecto, surge del movimiento para realizar su promesa en aquel espacio y en aquel tiempo histórico. [...] Por otra parte, el movimiento es siempre portador de proyecto, es decir, ya contiene en sí mismo, potencialmente, la institución. El estado naciente es efímero, incluso inaprensible, o tiende a la perpetuación. Además, surge del desorden, en el punto máximo del desorden, pero es un proceso de constitución del orden, un hacerse del orden, el orden en su hacerse. La institución es, por ello, el destino del movimiento, de su rendición a lo existente. En este sentido, es su heredera, pero, al mismo tiempo, su traición. (ALBERONI, 1984, p. 13). 
En este caso, la traición al movimiento refiere a que, tras la agitación y el tumulto, los presidentes elegidos le han fallado a su país. El proyecto político del gobierno entrante se aleja de los pueblos, olvida todos los niveles de los procesos colectivos de grupo: los medios, las motivaciones, las normas y los valores (ALBERONI, 1984). De hecho, "los presidentes en las democracias deliberativas tienden a sufrir cambios abruptos en popularidad: un día son aclamados como salvadores providenciales, y al siguiente son maldecidos como sólo los dioses caídos pueden ser" (O’DONNELL, 1994, p. 62). Generalmente como resultado de los efectos de los paquetes de ayuda o asistencia internacional.

Los préstamos de organizaciones como el FMI vienen condicionados con una serie de compromisos basados en políticas económicas que un país esté dispuesto a adoptar, la cuestión es que para los países con democracias delegativas, sumidos en crisis económicas, políticas y sociales, muchas de las medidas han representado un golpe brutal. Ante ello, O’Donnell (1994) establece que para enfrentar las crisis debe haber instituciones fuertes, pero para ello es necesaria una segunda transición democrática, ya que la primera se enfocó a obtener elecciones democráticas, que fue lo que consiguieron las Revoluciones de Colores.

Los nuevos tipos de democracias - como los que surgen después de una Revolución de Color - no deben relacionarse con el régimen anterior, sino con el proceso de transición, "así como el grado de severidad de los problemas socioeconómicos que heredan los gobiernos democráticos recientemente instalados (O’DONNELL, 1994, p. 55). El aporte de O’Donnell (1994) es muy interesante ya que si bien, estas nuevas democracias cumplen con los requerimientos de Dahl para la definición de poliarquía, tales no podrían llegar a convertirse en democracias representativas por su falta de consolidación o institucionalización, y por esto es que las denominacomo democracias delegativas, porque todo el poder se delega a la figura del presidente.

Mientras que en las democracias representativas el papel de las instituciones es vital en cuanto a la organización y la representación en el proceso político, las democracias delegativas "se basan en la premisa de que quienquiera que gane la elección a la presidencia tiene derecho a gobernar como lo crea conveniente, limitado sólo por los hechos duros de las relaciones de poder existentes y por un mandato constitucionalmente limitado" (O’DONNELL, 1994, p. 59).

\section{Consideraciones finales}


La democracia en el mundo no termina de salir de la crisis de representatividad en que se ha visto inmersa desde el fin del "siglo corto" que considera Hobsbawm (1998), que culmina con la caída del muro de Berlín, que si bien implicó al modo de ver de Huntington una "Tercera Ola de la Democracia”, también abrió el camino para la consolidación del modelo neoliberal que convirtió a la democracia en un rito cada vez más carente de representatividad y de control sobre la soberanía de los Estados ante el peso de los centros financieros internacionales.

Pero por otro lado, dió pie para la promoción desde occidente, y de manera más directa, aunque no exclusiva, desde los Estados Unidos, para impulsar, fortalecer y reorientar movimientos internos de reivindicaciones democráticas en países que no se integraban plenamente al modelo neoliberal y al reconocimiento de la unipolaridad bajo la hegemonía norteamericana. De esta manera las llamadas "Revoluciones de Colores" se constituyeron en efectivas formas de derrocar gobiernos que parecían alinearse con una opción que cuestionaba el mando único mundial y el modelo económico impuesto por el capital financiero con el fin del socialismo europeo y del Estado de Bienestar. Además, estas revoluciones contaron con la legitimidad que les dió el tener su origen en un descontento interno auténtico, si bien alimentado y reorientado hacia los intereses del capital internacional.

Por el contrario, tratándose de gobiernos democráticos antineoliberales, la fórmula vino a ser los llamados "golpes suaves" sustentados en la intervención de los poderes legislativo y judicial para derrocar gobiernos, como sucedió en América Latina, como fue en Honduras, Paraguay y Brasil.

Sin embargo, el doble discurso del apoyo de Estados Unidos, sus ONG y la Unión Europea quedó evidenciado cuando en 2006 se presentó un fuerte movimiento contra un fraude electoral, con movilizaciones superiores a las de cualquiera de los otros movimientos que dieron origen a las Revoluciones de Colores, y con una mayor cantidad de hechos probados que violentaban la legalidad electoral y un minúsculo margen de diferencia a favor del candidato oficial, pero dado que en este caso se trataba de la continuidad de uno de los alumnos más obedientes de las políticas neoliberales, amenazada con la candidatura opositora antineoliberal, no sólo no se generó apoyo alguno a lo que pudo ser la "Revolución Amarilla", sino que el cuestionado "triunfo" del candidato oficialista se vió acompañado del apoyo mediático internacional.

Con ello, aunado a los "golpes suaves" quedó más que evidente que lo que algunos han llamado la "internacional capitalista" no tiene realmente interés alguno en promover la 
democracia, sino que por el contrario, esta sólo importa en la medida en que responde a los intereses del capital internacional y a la geopolítica norteamericana.

\section{REFERÊNCIAS}

ALBERONI, F. Movimiento e institución: teoría general. Madrid, España: Editora Nacional, 1984.

ÅSLUND, A.;MCFAUL, M. Introduction: Perspectives on the Orange Revolution. Revolution in Orange: The origins of Ukraine's democratic breakthrough. Carnegie Endowment for International Peace, 2006. Disponible em: <http://carnegieendowment.org/files/AslundIntr1.pdf>. Acesso em: 20 nov. 2018

BAUTISTA, R.¿Cómo se produce una "Revolución de Colores”?Rebelión, 2018. Disponible em: <http://www.rebelion.org/noticia.php?id=237199>. Acesso em: 20 nov. 2018

BEVIR, M. Democratic governance. Nueva Jersey, Estados Unidos: Princeton University Press, 2010.

BRILL, M. Lessons of "The Tulip Revolution" Testimony prepared for the Commission of Security and Cooperation in Europe hearing on Kyrgyzstan's Revolution: Causes and consequences. Carnegie Endowment for International Peace, 2005. Disponible en: <http://carnegieendowment.org/files/olcotttestimony-April7-05.pdf>. Acesso en: 20 nov. 2018.

British Helsinki Human Rights Group. Why did voters in Belarus reject the "Denim Revolution"?. Global Research, 2006. Disponible em: <https://www.globalresearch.ca/whydid-voters-in-belarus-reject-the-denim-revolution/2207>. Acesso em: 20 nov. 2018.

BURGER, E.; MINCHUK, V. Alyaksandr Lukashenka's consolidation of power. En FORBRIG, J.; MARPLES, D. R.; DEMES, P. (Ed.). Prospects for democracy in Belarus. Washington, D. C., Estados Unidos: The German Marshall Fund of the United States, 2006.47-56. Disponible en: <http://pdf.kamunikat.org/1944-1.pdf>. Acesso en: 20 nov. 2018.

CHEEMA, G. S. Building democratic institutions: governance reform in developing countries. Bloomfield: Kumarian Press, 2005.

CONSEJO COORDINADOR EMPRESARIAL. Trabajamos por México. 2018. Disponible em: <http://www.cce.org.mx/trabajamos-por-mexico/>. Acesso em: 20 nov. 2018.

FUKUYAMA, F.The end of history?. The National Interest, 1989, p. 3-18.

GUTIÉRREZ DEL CID, A. La Revolución Naranja en Ucrania y la estrategia de Rusia.

Revista de Relaciones Internacionales de la UNAM, 2007. Disponible en

<http://revistas.unam.mx/index.php/rri/article/viewFile/18430/17506>. Acesso em: 10 out. 2018. 
HOBSBAWN, E. Historia del Siglo XX. Buenos Aires, Argentina: Crítica Grijalbo Mondadori, 1998.

HUNTINGTON, S. La Tercera Ola: la democratización a finales del sigloXX. México DF, México: Editorial Paidós, 1994.

HUNTINGTON, S. El choque de civilizaciones. México DF, México: Editorial Paidós, 2001.

HUSKEY, E. Kyrgyzstan's Tulip Revolution: Interview with Roza Otunbayeva.

Demokratizatsiya, 2006. Disponible em:

<http://demokratizatsiya.pub/archives/13_4_VG5927706116J714.pdf>. Acesso em: 20 nov. 2018.

JIMÉNEZ CANO, R. Twitter, herramienta para la revolución en Moldavia. El País, 2009. Disponible em:

<https://elpais.com/tecnologia/2009/04/08/actualidad/1239179279_850215.html>. Acesso em: 20 nov. 2018.

KANDELAKI, G. Georgia's Rose Revolution: A participant's perspective. USIP Special Report, 2006. Disponible en: 〈http://www.usip.org/sites/default/files/resources/sr167.pdf〉. Acesso en: 20 nov. 2018.

KARATNYCKY, A. Ukraine's orange revolution. Foreign affairs, 2005. Disponible en: <https://edocs.uis.edu/Departments/LIS/Course_Pages/LIS411/readings/Karatnycky_Ukraine _Orange_Revolution.pdf $>$. Acesso en: 20 nov. 2018.

KOLODIY, D.; ZIELYK, P.; KOLODIY, D. (director). The orange chronicles [cinta cinematográfica]. DK Productions, 2007. Disponible em:

<https://www.youtube.com/watch?v=dL-1mCHffgI>. Acesso em: 20 nov. 2018.

LA PRIMERA “Revolución Twitter” en Moldavia, cuatro años después. HotNews, 2013. Disponible em: <https://espanol.hotnews.ro/stiri-moldavia-14623773-primera-revolucintwitter-moldavia-cuatro-aos-despus.htm>. Acesso em: 20 nov. 2018.

LAS GUERRAS DE YUGOSLAVIA. EI País, 2011. Disponible em:

<http://internacional.elpais.com/internacional/2011/05/26/actualidad/1306360811_850215.ht ml>. Acesso em: 20 nov. 2018.

LETAIN, M. The 'Denim Revolution': A glass half full. Open Democracy, 2006. Disponible em: <https://www.opendemocracy.net/globalization-

institutions_government/denim_3441.jsp>. Acesso em: 20 nov. 2018.

LINZ, J. Una interpretación de los regímenes autoritarios. Papers: Revista Sociológica, 1978. Disponible em: <https://papers.uab.cat/article/view/v8-linz>. Acesso em: 20 nov. 2018.

MANNING, P. Rose-colored glasses? Color Revolutions and cartoon chaos in postsocialist Georgia. Cultural Anthropology, 2007. Disponible em:

<http://www.culanth.org/articles/209-rose-colored-glasses-color-revolutions-and>. Acesso em: 20 nov. 2018. 
MARPLES, D. The presidential election campaign: an analysis. En FORBRIG, J.;

MARPLES, D. R.; DEMES, P. (Ed.). Prospects for democracy in Belarus. Washington, D. C., Estados Unidos: The German Marshall Fund of the United States, 2006.95-101. Disponible em: 〈http://pdf.kamunikat.org/1944-1.pdf〉. Acesso em: 20 nov. 2018.

MITCHELL, L. Georgia's Rose Revolution. Current History, 2004. Disponible em: <http://webcache.googleusercontent.com/search?q=cache:44zD_qG3ba4J:academiccommons. columbia.edu/download/fedora_content/download/ac:138699/CONTENT/rose_revolution.pdf $+\& \mathrm{~cd}=3 \& \mathrm{hl}=\mathrm{es} \& \mathrm{ct}=\mathrm{clnk} \& \mathrm{gl}=\mathrm{mx}>$. Acesso em: 20 nov. 2018.

MORLINO, L. Democracias y democratizaciones. México DF, México: Centro de Estudios de Política Comparada, 2005.

MOSCOVICI, S. La era de las multitudes: un tratado histórico de psicología de las masas. México DF, México: Fondo de Cultura Económica, 1985.

MUNGIU-PIPPIDI, A.; MUNTEANU, I. Moldova's “Twitter Revolution”. Journal of Democracy, 2009. Disponible en: <http://www.sar.org.ro/wpcontent/uploads/2012/01/Moldova-Twitter-Revolution.pdf>. Acesso en: 20 nov. 2018.

O’DONNELL, G. Delegative democracy. Journal of Democracy, 1994. Disponible em: $\langle$ https://muse.jhu.edu/article/225426/pdf $>$. Acesso em: 20 nov. 2018.

ORUÉ, M. Tercera parte: Kirguistán. Em: ZUBELZÚ, G. (Ed.). Sistemas políticos, Revoluciones de Colores, y perspectivas: Los casos de Georgia, Ucrania y Kirguistán. Buenos Aires, República Argentina: Consejo Argentino para las Relaciones Internacionales, 2007. 39-52. Disponible em: 〈http://www.cari.org.ar/pdf/revoluciones-de-colores.pdf > Acesso em: 20 nov. 2018.

PAPAVA, V. Anatomical pathology of Georgia's Rose Revolution. Current Politics and Economics of the Caucasus Region, 2009. Disponible em:

<http://www.papava.info/publications/Papava_Anatomical\%20Pathology\%20Georgia's\%20T he\%20Rose\%20Revolution.pdf>. Acesso em: 20 nov. 2018.

\section{PARLIAMENTARY ELECTIONS. Office for Democratic Institutions and Human}

Rights, 2003. Disponible em: <http://www.osce.org/odihr/elections/georgia/70118>. Acesso em: 20 nov. 2018.

PÉREZ FERNÁNDEZ DEL CASTILLO, G. México 2006 Las elecciones que dividieron al país México. México DF, México: Miguel Ángel Porrúa, 2008.

REVOLUCIÓN de los Tulipanes fue la primera injerencia de EEUU en Asia Central, cree el expresidente kirguís. Sputnik, 2015. Disponible en:

<https://mundo.sputniknews.com/politica/201503171035449642/>. Acesso en: 20 nov. 2018.

SANNIKOV, A.; KULEY, I. Civil society and the struggle for freedom. En FORBRIG, J., MARPLES, D. R.; DEMES, P. (Ed.). Prospects for democracy in Belarus. Washington, D. C., Estados Unidos: The German Marshall Fund of the United States, 2006. 57-64. Disponible em: 〈http://pdf.kamunikat.org/1944-1.pdf〉. Acesso em: 20 nov. 2018. 
SCHUMPETER, J. Capitalismo, socialismo y democracia. Madrid, España: Aguilar, 1963.

SEN, A. Desarrollo y libertad. Buenos Aires, Argentina: Planeta, 2000.

SHARP, G. De la dictadura a la democracia: un sistema conceptual para la liberación. 2011.Disponible em: <https://www.aeinstein.org/wp-content/uploads/2013/09/DelaDict.pdf>. Acesso em: 20 nov. 2018.

TAMAYO, J. Las formas nuevas de los movimientos sociales en el nuevo siglo.

Movimientos sociales, autonomía y resistencia. Guadalajara, México: Universidad de Guadalajara-California-México: Studies Center CSU, 2013.

TAYLOR, P.; FLINT, C. Geografía política: Economía-mundo, Estado-nación y localidad. Madrid, España: Trama Editorial, 2002.

VENTILA, D. Moldavia: ¿hacia un Nuevo giro político?. Real Instituto Elcano, 2010. Disponible en: <file://C:/Users/starer/Downloads/ARI67-2010_Vintila_Moldavia1\%20(1).pdf>. Acesso en: 20 nov. 2018.

WELT, C. Georgia: Causes of the Rose Revolution and lessons for democracy assistance. USAID, 2005. Disponible em: <http://csis.org/files/media/csis/pubs/ci.causesroserevolution.03.05.pdf >. Acesso em: 20 nov. 2018.

YORK, S.; MERRIMAN, H.; ZIMMERMAN, M.; BOAZ, C. Orange Revolution study guide. The International Center on Nonviolent Conflict, 2010. Disponible en:

$<$ http://www.orangerevolutionmovie.com/pdf/orange-revolution-study-guide.pdf $>$. Acesso en: 20 nov. 2018.

ZÁRATE, A. Luis Carlos Ugalde, el gran mago de la política. El Universal, 2006.

ZHURZHENKO, T. Europeanizing the ukrainian-russian border: From EU enlargement to the "Orange Revolution". Debatte: Journal of Contemporary Central and Eastern Europe, 2005. Disponible en:

<http://www.bundesheer.at/pdf_pool/publikationen/ukraine_zerissen_zw_ost_u_west_m_mal ek_ukraines_border_t_zhurzhenko.pdf>. Acesso en: 20 nov. 2018.

\section{Como referenciar este artigo}

TAMAYO, Jaime.; IÑIGUEZ, Daniela. As crises das democracias e as revoluções das cores. Rev. Sem Aspas, Araraquara, v. 7, n. 1, p. 4-32, jan./jun., 2018. ISSN: 2358-4238. DOI: 10.29373/semaspas.unesp.v7.n1.jan/jun.2018.11851

Submetido em: 19/10/2018

Aprovado em: 10/11/2018 